\title{
A PRELIMINARY REPORT ON THE CRYSTALLINE INORGANIC COMPONENT OF BONE IN PAGET'S DISEASE
}

\author{
BY \\ H. O. WILLIAMS \\ From the Laboratories of the David Lewis Northern Hospital, Liverpool
}

(RECEIVED FOR PUBLICATION MAY 27, 1953)

In the course of an extensive study of bone from cases of Paget's disease, it has become apparent that the disease represents a departure from the normal in both structyral and physical constitution. With the belief that these abnormalities must be reflected in the lowest limits of organization of the tissues, a study of the crystalline inorganic component was undertaken.

Inspired by Robinson (1952a) the techniques of electron microscopy and electron diffraction were employed. This report is based on the examination of a specimen of ashed bone obtained from the tibia of an undoubted case of generalized Paget's disease in a female of 71 years (Fig. 1).

\section{Procedure}

Bone was obtained from the tibia in the area shown in Fig. 2, and the block divided longitudinally into two halves. One half was decalcified electrolytically, and paraffin sections prepared by the usual technique and stained with haematoxylin and eosin (Fig. 3). Areas representing the grossest changes were selected (Fig. 4), and from the undecalcified half the corresponding areas were removed by micro-dissection. Adherent muscle and fibrous tissue were removed mechanically, and the pieces of bone ashed in a muffle furnace at $400^{\circ} \mathrm{C}$. The resulting material was then used for examination.

The specimen was first crushed on a microscope slide, and a $0.5 \%$ solution of formvar in ethylene dichloride was poured over the slide and allowed to dry. The film of formvar plus specimen was floated off the microscope slide in the usual way and mounted on a copper grid for insertion into the specimen stage of the microscope, a standard Metropolitan-Vickers electron microscope E.M.3.

\section{Results}

It was found that the specimen consisted of both finely divided material and small flakes (Fig. 5). The finely divided material was shown to consist mainly of $\mathrm{CaNaPO}_{4}$ by its electron diffraction pattern, while $\mathrm{NaF}, \mathrm{CaO}$, and $\mathrm{Na}_{2} \mathrm{O}$ were identified in the small flakes (Fig. 6).

The inorganic crystalline component of normal bone is hydroxyapatite (Bale, 1940) with a basic formula of $\mathrm{Ca}_{10} \mathrm{P}_{6} \mathrm{O}_{26} \mathrm{H}_{2}$, while $\mathrm{Na}, \mathrm{Mg}, \mathrm{Ca}$, and $\mathrm{PO}_{4}$ are believed to be in the cement substance in which the crystals lie, and $\mathrm{CO}_{3}$ which has a surface relationship to the inorganic crystalline hydroxyapatite.

No trace of any apatite could be observed in these experiments. The main constituent was

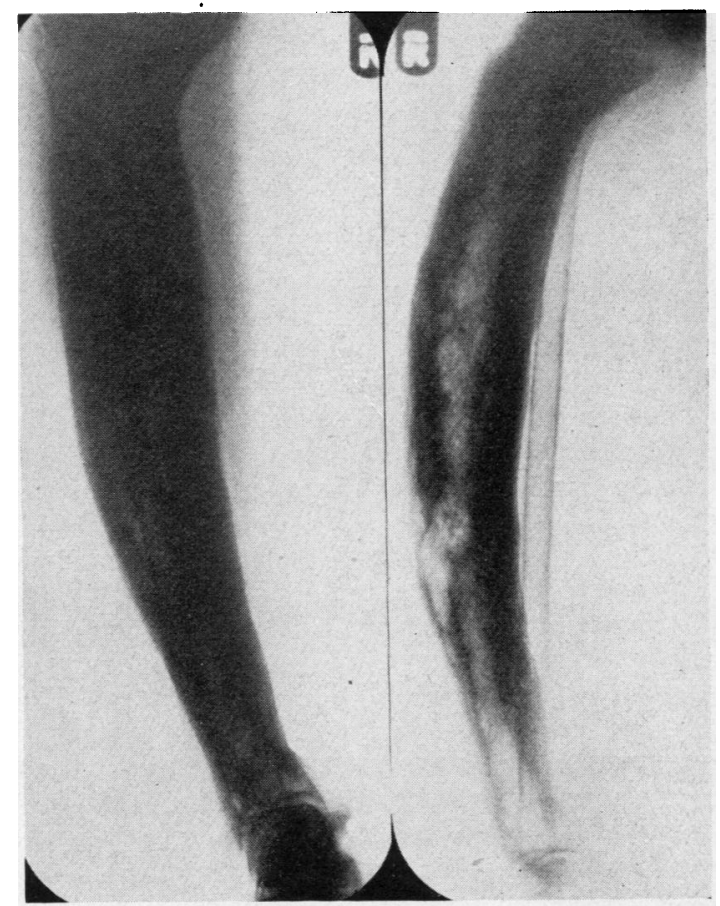

FIG. 1.-Radiograph of bones from which the material was obtained, showing gross changes of Paget's disease. 
Fig. 2.-Radiograph of the selected area from the lateral tibial condyle obtained by direct contact method with the bone slice.

FIG. 3.-A low-power view of the area showing total replacement of normal bone by the osteitic process. Haematoxylin and eosin, $\times 45$.

FIG. 4.-A high-power view of the same area. Haematoxylin and eosin, $\times 130$.

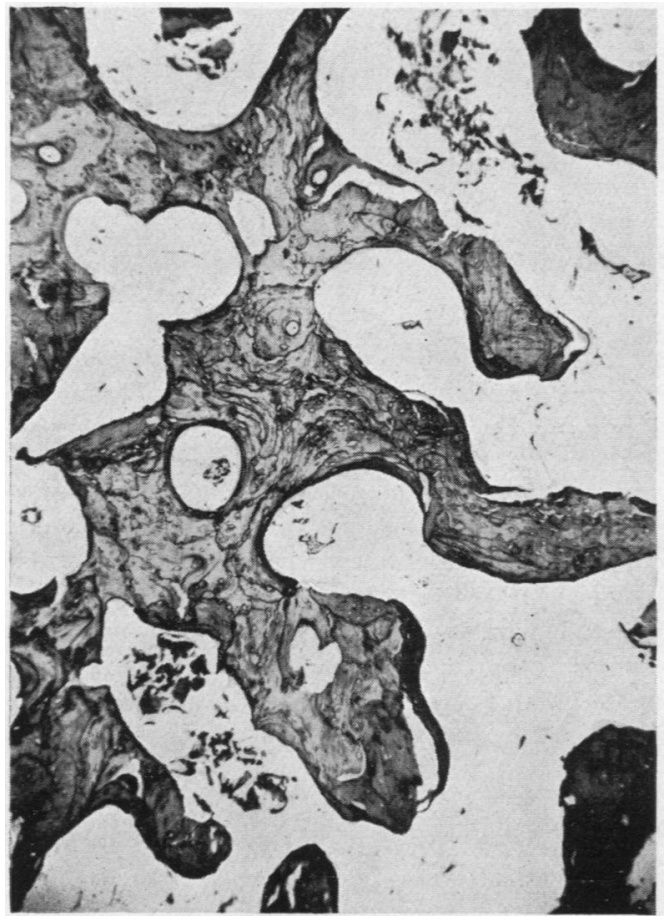

FIG. 3.

$\mathrm{CaNaPO}_{4}$. This, together with the rather surprising findings of $\mathrm{Na}_{2} \mathrm{O}$ and particularly $\mathrm{NaF}$, suggests that a much larger amount of sodium is present than would normally be expected. The effect of heat produced by the electron beam on the specimens may explain the presence of calcium and sodium oxides, for it has been found that specimens whose melting points lie well above

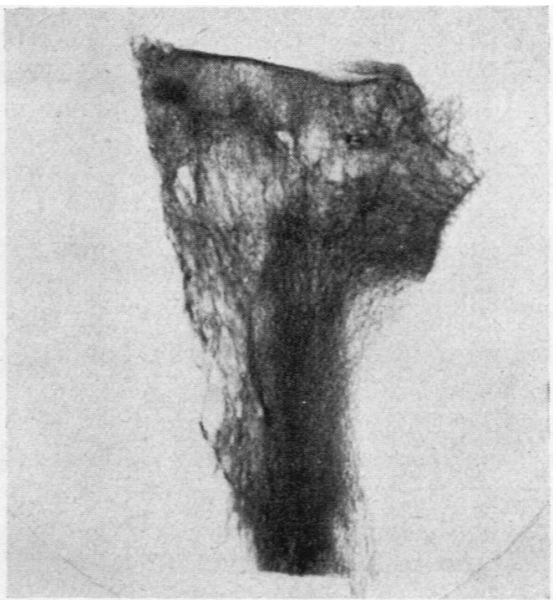

FIG. 2.

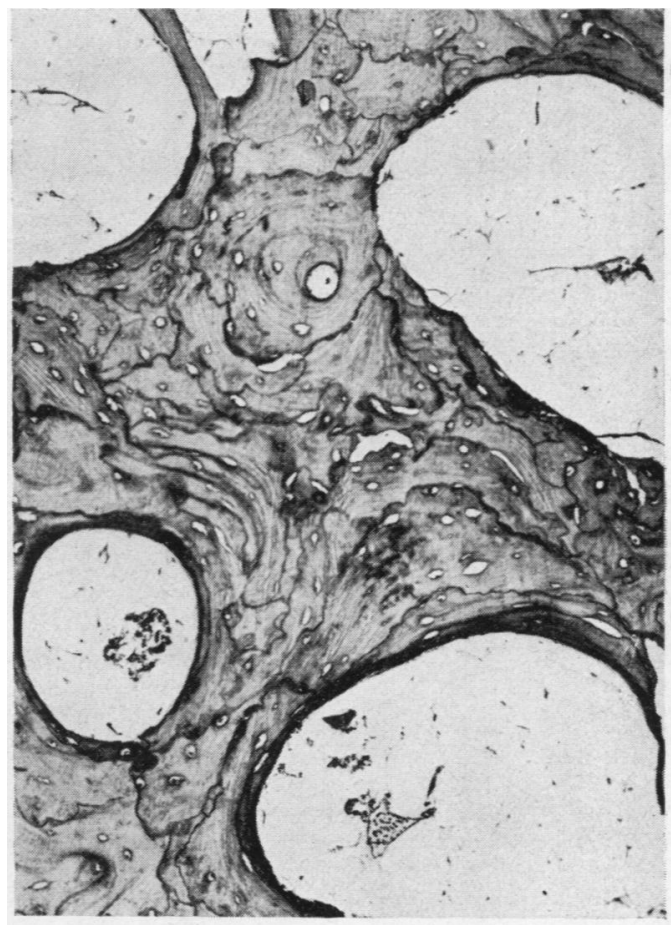

Fig. 4.

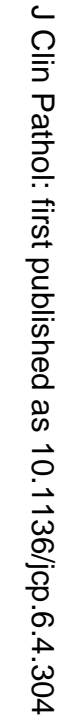

$1,000^{\circ}$ can be melted in the microscope by increasing the intensity of the electron beam, and it is probable that even under normal working conditions the temperature of the specimen may be quite high.

\section{Conclusion}

Assuming that apatite was the main initial constituent it would be expected that the apatite struc- 
ture would be retained even if $\mathrm{CO}_{2}$ were liberated by the heat, for, as pointed out by Robinson (1952a), heating in excess of $400^{\circ}$ does not alter the nature of the inorganic crystals of normal bone, but merely increases their size, and the tendency is to give even sharper diffraction patterns because the crystals are larger after heating due to fusion of smaller crystals : they remain hydroxyapatite. It seems likely, therefore, that the nature of the inorganic crystals of the bone of Paget's disease may differ significantly from normal. Robinson (1952b) intimated that his preparation from bone from a case of Paget's disease had not been satisfactory, and in later discussion felt that it might well have been because the bone sections that he prepared might have indicated a different structure from that which he had expected.

The results of this investigation of ashed bone seem to indicate that the inorganic crystalline

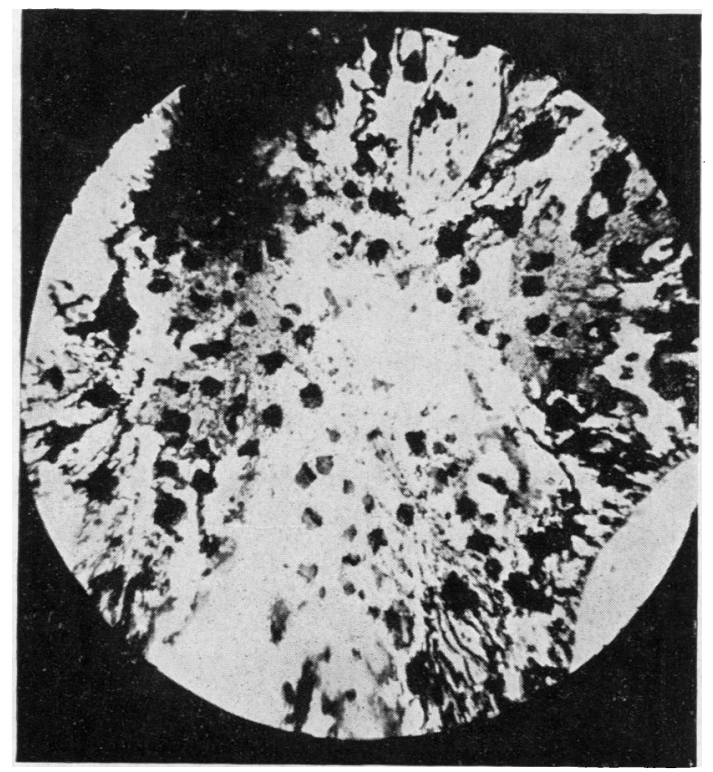

Fig. 5.-An electron micrograph of the material used for electron diffraction, showing the amorphous material and the flakes referred to in the text, $\times 2,500$.

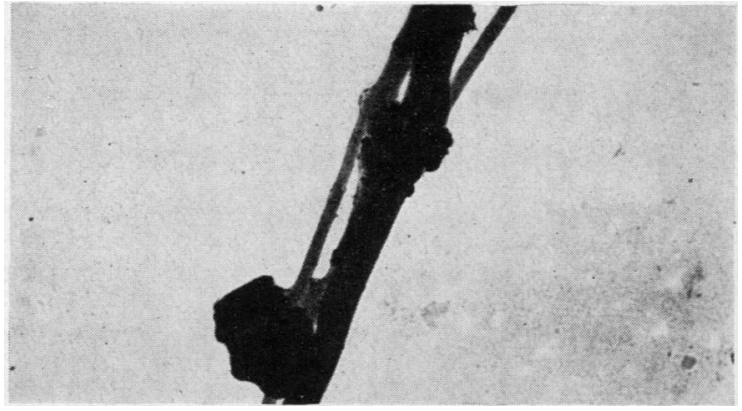

FIG. 6.-An electron micrograph of one of the flakes which gave the diffraction patterns of $\mathrm{NaF}, \mathrm{CaO}$, and $\mathrm{Na}_{2} \mathrm{O}, \times 34,000$.

phase may not be that of the hydroxyapatite pattern. Great care was taken at the outset to use for this analysis only areas showing the grossest changes of Paget's disease in order to exclude as far as possible areas of unreplaced normal bone from the experiment.

It is emphasized that these results are based on the study of material from a single case and will need confirmation from other specimens in order to assess the constancy of results, and in particular to estimate further the significance of the excess sodium content and the fluoride noted in these experiments. Further investigation of this matter is proceeding, and, following the work of Robinson (1952a), an effort is being made to determine the relationship of the crystalline inorganic component of bone in Paget's disease to the organic matrix.

Grateful thanks are due to Drs. R. S. Graham and G. Waghorn for assistance with the electron microscope, and for the interpretation of the diffraction patterns ; to Dr. R. A. Robinson, whose work inspired this study, and whose later helpful advice has been a source of great encouragement; and to Professor Bryan L. McFarland for his enthusiasm and help at all times.

\section{REFERENCES}

Bale, W. F. (1940). Amer. J. Roentgenol., 43, 735

Robinson, R. A. (1952a). J. Bone Jt Surg., 34A, 389. - (1952b). Personal communication. 